\title{
Morphological Aspects of the Larval Instars of Chrysomya albiceps (Diptera, Calliphoridae) Reared in the Laboratory
}

\author{
Margareth Maria de Carvalho Queiroz/ ${ }^{+}$, Rubens Pinto de Mello*, \\ Marli Maria Lima
}

\author{
Laboratório de Biologia e Controle de Insetos Vetores, Departamento de Biologia \\ *Laboratório de Díptera, Departamento de Entomologia, Instituto Oswaldo Cruz, Av. Brasil 4365, 21045-900 \\ Rio de Janeiro, RJ, Brasil
}

In order to study the morphology of young Chrysomya albiceps forms, newly hatched larvae were collected at $2 \mathrm{hr}$ intervals, during the first $56 \mathrm{hr}$; after this time the collection was made at $12 \mathrm{hr}$ intervals. For identification and drawing, larvae were placed between a slide and a coverslip. The cephalopharyngeal skeletons along with the first and last segments were cut off for observation of their structures and spiracles. The larvae present microspines, which are distributed randomly throughout the 12 segments of the body surface; the cephalopharyngeal skeleton varies in shape and extent of sclerotization according to larval instar; the second and third instars have relatively long processes (tubercles) on the dorsal, lateral and ventral surfaces, with microspine circles on the terminal portion.

Key words: blowfly - Chrysomya albiceps - larval morphology

Guimarães et al. (1978) were the first researchers who recorded the presence of Chrysomya albiceps (Wiedemann, 1819), Chrysomya megacephala (Fabricius, 1974) and Chrysomya putoria (Wiedemann, 1818) in Brazil. According to them, these species were probably introduced in the southern region of Brazil by ships coming from Angola, Africa. These Diptera are considered important from the sanitary standpoint, since they may be mechanical vector of enteropathogens for humans as well as cause facultative myiasis. Today, they are widely distributed throughout the neotropical region (Prado \& Guimarães 1982, Baumgartner 1988), and have drawn the attention of several researchers. However, only the last two species have been well studied in terms of biology and taxonomy of the adults. The taxonomy of C. albiceps is still quite unknown since it was long thought to be indistinguishable from those of $C$. rufifacies (Macquart, 1842) (Patton 1922, Zumpt 1965, Kurahashi 1981, Richard \& Gerrish 1983), a species that has not yet been recorded in Brazil. However, more accurate observations have shown some morphological aspects of the third instar of both species that allow their differentiation (Erzinçlioglu 1987, Tantawi \& Greenberg 1993).

\footnotetext{
*CNPq research fellow

+Corresponding author. Fax: +55-21-290.1146

Received 23 April 1996

Accepted 19 December 1996
}

During the 70's the two species were geographically isolated, C. albiceps being restricted to Africa and $C$. rufifacies to regions of Eastern Asia and Australia, although occupying the same biological niches in their respective natural biotopes (Baumgartner 1993).

Some behavioral aspects of $C$. albiceps, such as high dispersal rate, easy adaptation to new environments and a wide geographic distribution in our territory suggest that deeper studies should be conducted on the morphology of immature phases, since this would be useful for future field control programs. Thus, the purpose of the present study is to provide information on new morphological aspects, specially related to the first and second larvae.

\section{MATERIALS AND METHODS}

Newly hatched larvae of $C$. albiceps were obtained from adults maintained in the laboratory, according to the methodology of Queiroz and Milward-de-Azevedo (1991). The study was conducted in a climatic chamber regulated at $27 \pm 1^{\circ} \mathrm{C}$, $60 \pm 10 \%$ relative humidity and a $14 \mathrm{hr}$ photoperiod. After ovipositing, egg masses were collected, weighed and separated into three groups of $0.05 \mathrm{~g}$ each. The eggs were placed on Petri dishes lined with filter paper moistened with distilled water and incubated at $27^{\circ} \mathrm{C}$. After hatching, the larval groups were transferred to vessels containing $300 \mathrm{~g}$ diet, consisting of rotten horse meat (fresh meat thawed and kept in the refrigerator for 11 days and then heated to $27^{\circ} \mathrm{C}$ in a climatic chamber for $2 \mathrm{hr}$ ). 
A sample of ten larvae (three replications) was collected at $2 \mathrm{hr}$ intervals, during the first $56 \mathrm{hr}$; after this time the collection was made at $12-\mathrm{hr}$ intervals, until all mature larvae had abandoned the diet. The larvae of each sample were sacrificed, fixed in San Jean fluid heated to $60^{\circ} \mathrm{C}$ for one week and transferred to $70 \%$ alcohol for later study, when they were transferred to glass vessels containing lactophenol. Larval instars were characterized according to the number of spiracular openings and the presence or absence of anterior spiracles.

The larvae were placed between slide and coverslip for analysis and drawing. The cephalopharyngeal skeletons as well as the first and last segments were severed from their structure and spiracle structure for easier observation. The analysis and drawings were performed under the ligth microscope with a camera lucida. Scales were obtained by projecting a micrometer scale onto the light camera. The terminology used for the description of larval instars was that of Lopes (1943, 1982) and McAlpine et al. (1981).

\section{RESULTS}

Description of the larvae - Figs 1 to 11 - First instar - Body composed by 12 segments separated by groups of spines with different shape, size and position, arranged in rows in the limit of all segments (Fig. 1).

Pseudocephalon membranous and wide, with a slight narrowing close to the palps and antennae with an oral cristae in the preoral cavity; palps and antennae conspicuous; the first thoracic segment surrounded by groups of robust spines that vary in size and shape (generally widened) and positioned laterally above the atrium. Suprabuccal teeth and cephalopharyngeal skeleton slightly chitinized (Figs 1, 2, 3).

Labial sclerite (maxilla) formed by a pair of symmetrical parts articulated at the base, wide, elongated and slightly chitinized; both present sharp and slightly curved apices; dental sclerite (dentate) poorly individualized and fully incorporated into the labial sclerite (Figs 2, 3, 4).

Hypostomal sclerite attached to the pharyngeal one and forming a wide forceps (Figs 2, 3, 4). Infra-hypostomal sclerite more developed than the others in the intermediate region; with a ventral prolongation corresponding to the median beam, below which is the salivary gland duct. When viewed dorsally and/or ventrally, it is $\mathrm{H}$ shaped, with the lateral branches articulating with an odd branch from which they detach easily. This part is inserted into the hypostomal sclerite, but its limits are well defined (Figs 2, 3, 4).

Infrapharyngeal sclerite barely visible and joined to the ventral branch of the pharyngeal sclerite where it gives rise to the formation of the canaliculi of the ventral surface of the pharyngeal lumen (Figs 2, 3).

Pharyngeal sclerite pigmented, presenting zones of greater or lesser pigment condensation; clypeal arch complete and chitinized, as also is the entire pharynx. Dorsal horn slightly larger than the ventral one and both have outer margins delineated by slightly pigmented parallel lines; the dorsal horn joins the ventral one through a narrow region which is more chitinized; the posterior region of the ventral horn has a more or less straight outer margin with an abrupt downward slope forming a long and sharp extremity (Figs 2, 3, 4).

The posterior end of the larva (segment 12) has a pair of posterior spiracles with only one spiracular opening; this segment presents a pair of ventromedial tubercles and a pair of anal tubercles; peritrema closed and slightly pigmented; the pair of spiracles is situated in a convex position in the median-apical region of the spiracular plate (Figs 5, 6).

Transition from first to second larval instar: pharata - Figs 7 to 17 - As observed by transparency, at $14 \mathrm{hr}$ the larvae present in the second thoracic segment a rudimentary anterior spiracle in formation that throughout time changes until it reaches its definitive second instar shape, when mounlt occurs (Figs 7, 8, 9, 13). The presence of first instar structures is observed basically in the cephalopharyngeal skeleton, together with the progressive formation of structures belonging to the second instar cuticle, i.e., the labial sclerite (maxillae) and the dentate sclerite that can be individualized; both are only slightly chitinized. These structures change throughout time and become more chitinized (Figs 10,11, 12).

The posterior spiracle of first instar larvae can be observed at the posterior end of segment 12, and by transparency, the formation of the posterior spiracle can be observed on the second instar cuticle, with two still incipient spiracular openings. In this segment and on the same second instar cuticle, three pairs of tubercles can be seen in the dorsal part: an inner-dorsal one, a dorsomedial one and a dorsal-external one, as well as three ventral tubercles: a ventral-external one, a ventromedian one and a ventral-internal one, as well as a pair of anal tubercles.

Second instar - Spines between segments are formed by one, two or three strongly pigmented tips. Beginning from the fourth segment (third thoracic segment) a laterodorsal, a dorsolateral and a dorsomedian pairs of tubercles are observed at dorsal surface and a lateroventral, a ventrolateral and a ventromedian pairs at ventral surface. These 


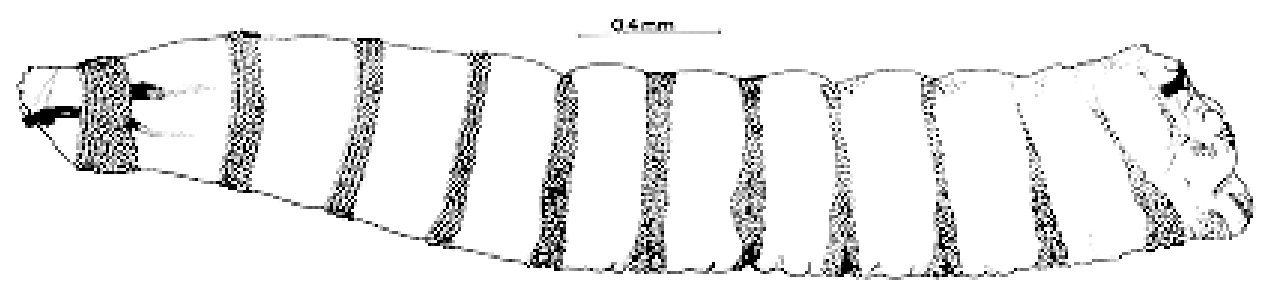

1
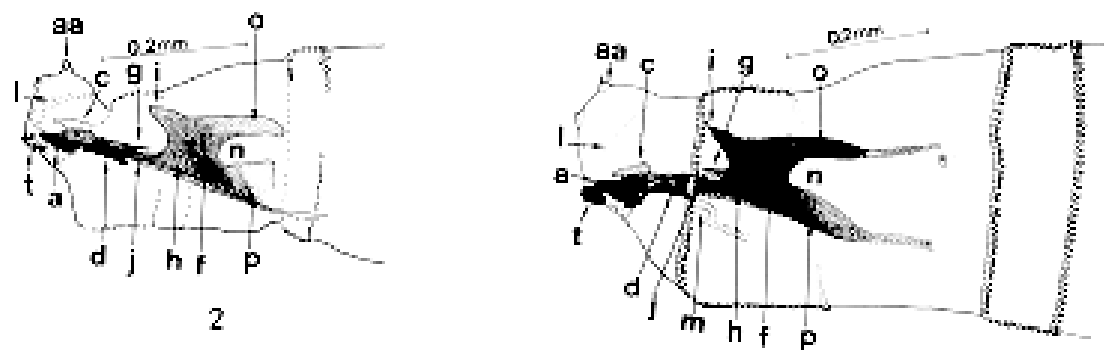

3
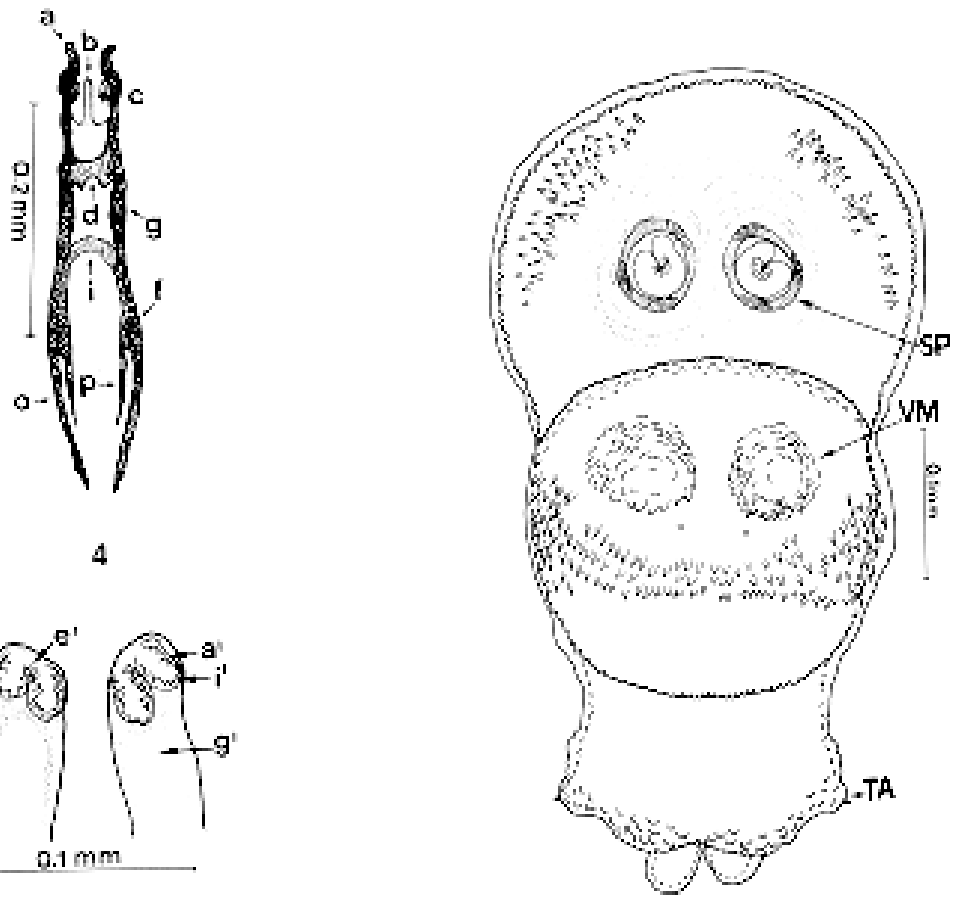

5

6

First larval instar of Chrysomya albiceps - Fig. 1: lateral vision; Fig. 2: lateral vision of anterior end (zero hr); Fig. 3: lateral vision of anterior end (12 hr); Fig. 4: ventral vision of cephalopharyngeal skeleton (12 hr); Fig. 5: spiracle posterior (zero hr); Fig. 6: ventral vision of posterior end ( $12 \mathrm{hr}$ ). Abbreviations: $a=$ antenna; $a=$ maxilla (buccal hook); $b=$ dental sclerite (dentate); $\mathrm{c}=$ mandible; $\mathrm{d}=$ hypopharyngeal sclerite (infra-hypostomal); $\mathrm{f}=$ pharyngeal sclerite; $\mathrm{g}=$ hypostomal sclerite (parastomal or paraclypeal bar); $h=$ clypeum; $i=$ clypeal arch; $j=$ infrapharyngeal sclerite; $1=$ oral cristae (atrium); $m=$ salivary gland duct; $n=$ median incision; $\mathrm{o}=$ dorsal horn; $\mathrm{p}=$ ventral horn; $\mathrm{t}=$ suprabuccal teeth; $\mathrm{a}^{\prime}=$ peritrema; $\mathrm{b}^{\prime}=$ fissure; $\mathrm{e}^{\prime}=$ spiracular plate; $\mathrm{g}^{\prime}=$ spiracular chamber; $\mathrm{i}^{\prime}=$ trabeculae; $\mathrm{SP}=$ posterior spiracle; $\mathrm{VM}=$ ventromedial tubercle; $\mathrm{TA}=$ anal tubercle. 


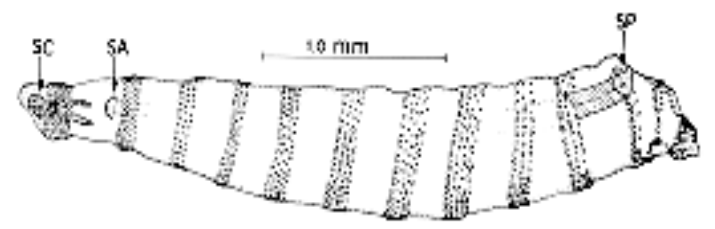

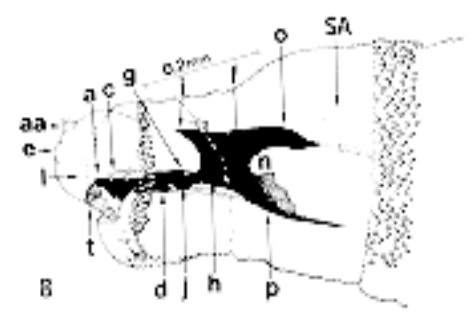

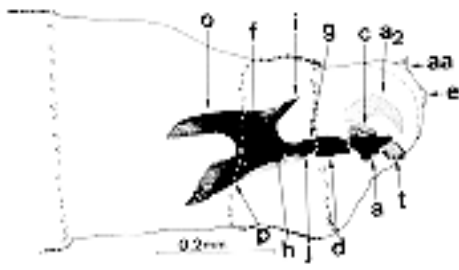

10

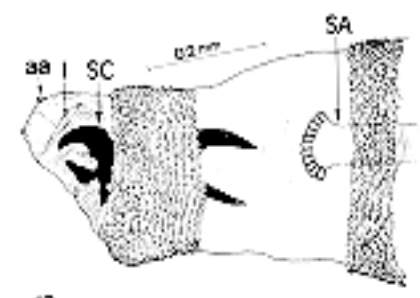

12
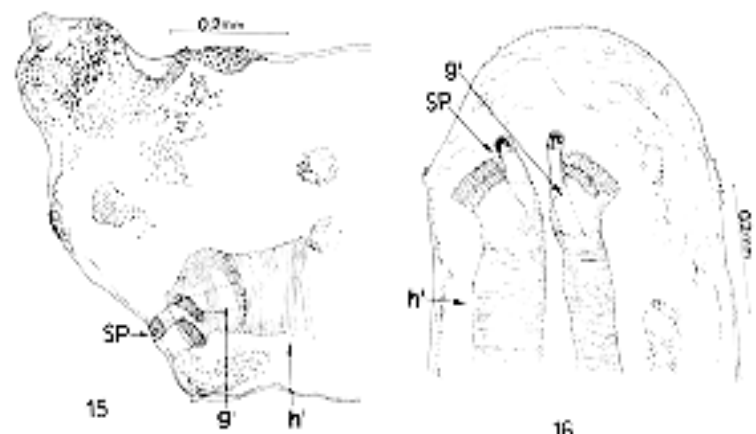

16

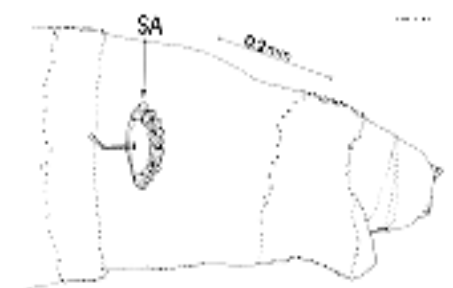

9
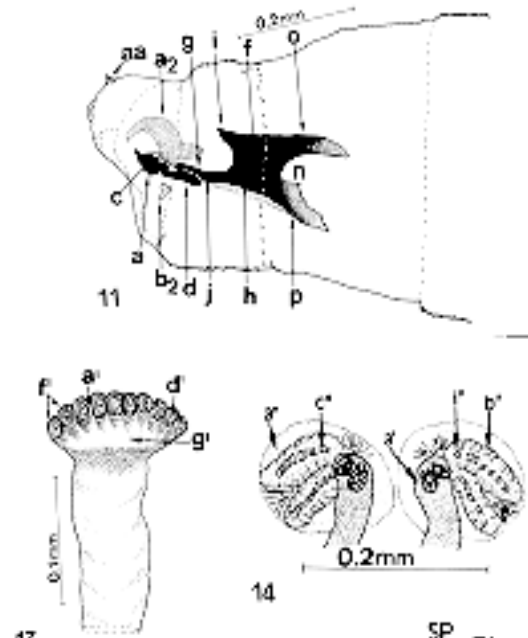

14

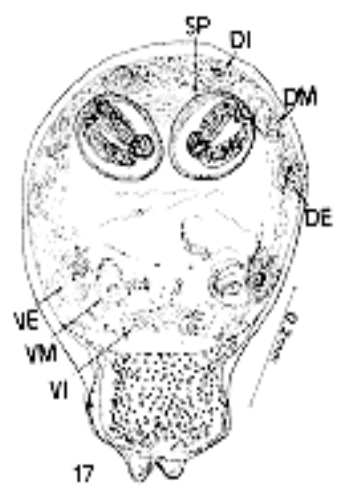

Transition from first to second larval instar (pharata) of Chrysomya albiceps - Fig. 7: lateral vision (20 hr); Fig. 8: lateral vision of anterior end (14 hr); Figs 9-10: lateral vision of anterior end (16 hr); Fig. 11: lateral vision of anterior end (18 hr); Fig. 12: lateral vision of anterior end ( $20 \mathrm{hr})$; Fig. 13: anterior spiracle ( $20 \mathrm{hr})$; Fig. 14: posterior spiracle ( $20 \mathrm{hr})$; Fig. 15: lateral vision of posterior end $(20 \mathrm{hr})$; Figs 16-17: ventral vision of posterior end $(20 \mathrm{hr})$. Abbreviations: aa= antenna; $\mathrm{a}=$ maxilla (buccal hook); $c=$ mandible; $d=$ hypopharyngeal sclerite (infra-hypostomal); $e=$ maxilary palp; $f=$ pharyngeal sclerite; $g=$ hypostomal sclerite (parastomal or paraclypeal bar); $h=$ clypeum; $i=$ clypeal $\operatorname{arch} ; j=$ infrapharyngeal sclerite; $1=$ oral cristae $($ atrium); $n=$ median incision; $\mathrm{o}=$ dorsal horn; $\mathrm{p}=$ ventral horn; $\mathrm{t}=$ suprabuccal teeth; $\mathrm{a}_{2}=$ maxilla (buccal hook); $\mathrm{b}_{2}=$ dental sclerite (dentate); $a$, a"= peritrema; $b "=$ fissure; $c^{\prime \prime}=$ spiracular opening; $d^{\prime}=$ spiracular orifice; $f^{\prime}=$ spiracular ramifications; $g^{\prime}=$ spiracular chamber; h'= trachea; $i$ "= trabeculae; $\mathrm{SC}=$ cephalopharyngeal skeleton; $\mathrm{SA}=$ anterior spiracle; $\mathrm{SP}=$ posterior spiracle; $\mathrm{VE}=$ external ventral tubercle; $\mathrm{VM}=$ ventromedial tubercle; $\mathrm{VI}=$ internal ventral tubercle; $\mathrm{DI}=$ internal dorsal tubercle; $\mathrm{DM}=$ dorsomedial tubercle; $\mathrm{DE}=$ dorsolateral process. 
tubercles present a crown of short, robust and strongly pigmented spines at their extremity (Figs 18, 19, 20).

Pseudocephalon with abundant fine, straight and branched oral cristae that converge toward the dental sclerite (Fig. 20).

Labial sclerite (maxillae and buccal hooks) strongly pigmented, with curved and dentate ends; the mandibles are incorporated into this sclerite. Dental sclerite visible and clearly separated from the labial sclerite. Ventral chitinous ring has the aspect of a plate (Figs 20,21).

Hypostomal sclerite consists of a small bar fully linked to the pharyngeal sclerite and located above the infrahypostomal sclerite (Figs 20, 21). Subhypostomal sclerite visible and located between the anterior branches of the infrahypostomal sclerite, presenting fused plates with dorsal separation (Figs 20, 21).

Chitinized infrapharyngeal sclerite found only in the anterior portion and joined to the ventral branch of the pharyngeal sclerite, where it gives way to the formation of longitudinal striae on the ventral surface of the pharyngeal lumen (Fig. 21).

Between the hypostomal and pharyngeal sclerites there is an ocular depression; pharyngeal sclerite and clypeal arch quite chitinized; final portion of the dorsal horn more or less tapered and only slightly chitinized; the horn has a window (an area also barely chitinized); ventral horn also has a window which is larger than that of the dorsal horn. Both horns present only slightly chitinized outer margins; final portion of the ventral horn larger and more rounded than that of the dorsal horn. Middle incision between the two horns well demarcated (Fig. 21).

In the second larval segment there is the anterior spiracle which is fully formed and presents ten to 12 spiracular branches with several orifices (Figs 20, 22).

Posterior end of the larva (segment 12) presents a pair of posterior spiracles with two openings each; peritrema closed and pigmented and located in a convex position in the median-apical region of the spiracular plate. In this segment there are three dorsally located tubercle pairs: a dorsal internal one, a dorsomedial one and a dorsal-external one; ventrally, there are three tubercle pairs: a ventralexternal one, a ventromedial one and a ventral-internal one. A pair of anal tubercles is present posteriorly (Figs 23, 24).

Transition from second to third larval instar: pharata - Figs 25 to 31 . Observation by transparency shows the formation of the anterior spiracle in the cuticle of the third larval instar, starting at $38 \mathrm{hr}$ (Fig. 26).

The cephalopharyngeal skeleton basically pre- sents the same structures as those of the second instar, but the progressive onset of third instar structures is also observed; the labial sclerite (maxillae) and the dorsal and ventral horns of the pharyngeal horns are only slightly chitinized; these structures change throughout time and become more chitinized and pigmented (Fig. 25).

The posterior spiracle of the second instar larva is observed in the posterior end (segment 12), and the formation of the posterior spiracle of the third instar larva is observed by transparency, presenting three spiracular openings.

Third instar - Cephalopharyngeal skeleton fully formed. Labial sclerite robust, fully pigmented, curved, and dentate; posterior part wider than the anterior part and sharply pointed; mandibles incorporated into this sclerite; dentate sclerite well individualized, and ventral chitinous ring well constituted.

Hypostomal sclerite strongly attached to the pharyngeal sclerite. Infrapharyngeal sclerite densely pigmented and chitinized in the anterior portion (less visible than in the second instar), joined to the pharyngeal one where it gives way to the striae of the ventral surface of the pharyngeal lumen (Fig. 28).

Hypopharyngeal sclerite $\mathrm{H}$ shaped, formed by two strongly chitinized stems which touch the labial sclerite anteriorly and the pharyngeal sclerite posteriorly; salivary gland duct below the hypopharyngeal sclerite (Fig. 28).

Pharyngeal sclerite well sclerotized and pigmented; clypeal arch highly chitinized; dorsal horn presents a longitudinal window on the posterior end which is slightly lighter in the pigmented zone; ventral horn also presents a window larger than that of the dorsal horn. A non-pigmented region posteriorly contiguous to the dorsal and ventral horns is also observed in this instar, and is larger in the dorsal horn. Outer margin of the dorsal horn barely sclerotized. Middle incision well demarcated (Fig. 28).

The posterior end of the larva (segment 12) presents a pair of posterior spiracles with three converging openings; between these openings we observed, for the first time in this instar, structures which seems to be of spiracular support; peritrema opened and quite sclerotized, situated in a convex position in the median-apical region of the spiracular plate. Three pairs of well separated tubercles are observed dorsally in this segment; a dorsal-inner one, a dorsomedial one and a dorsal external one; ventrally, there are three pairs of tubercles: a ventral-external one, a ventromedial one and a ventral-internal one; posteriorly there is a pair of anal tubercles with a crown of spines strongly pigmented in the terminal portion (Figs 29, 30). 


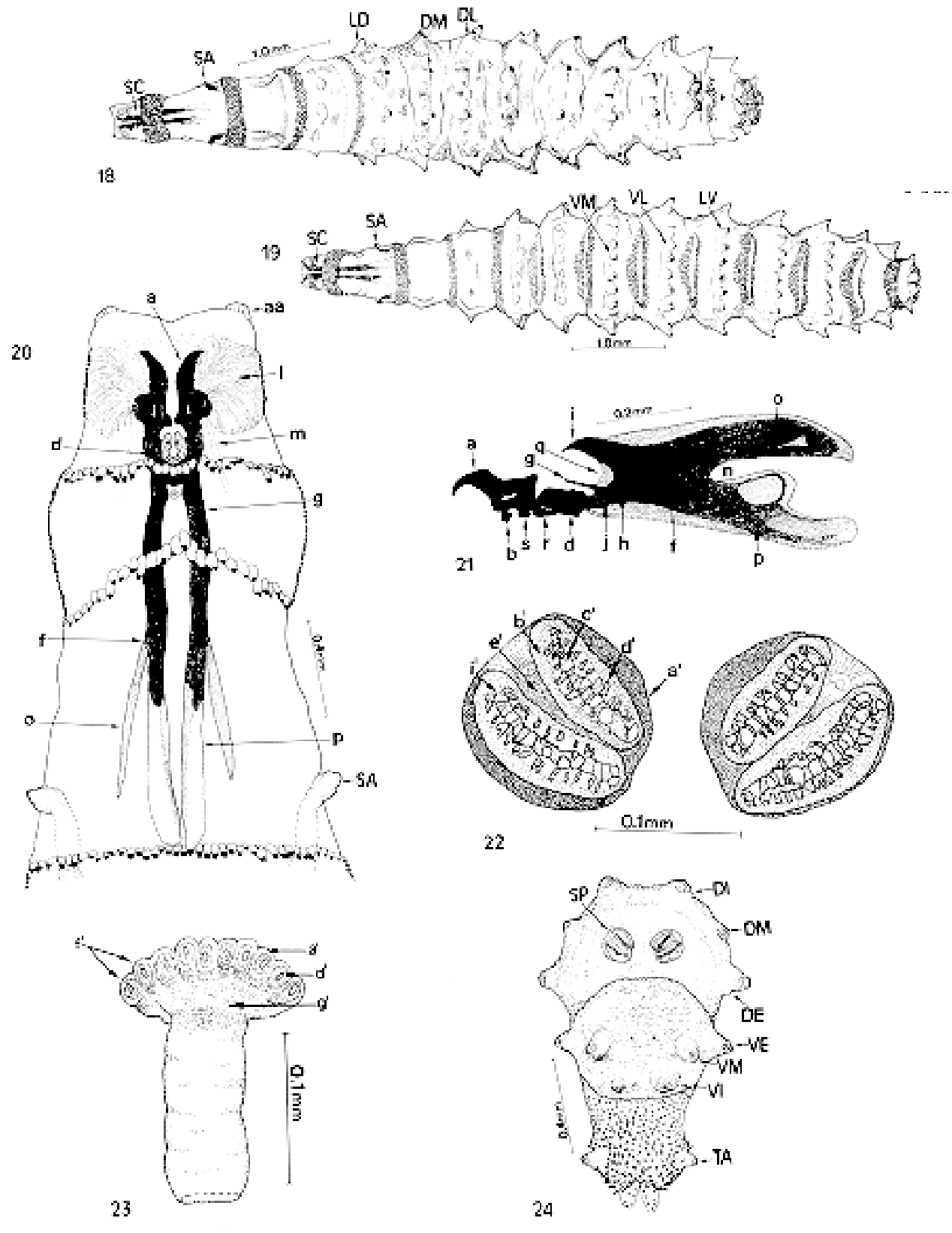

Second larval instar of Chrysomya albiceps (duration: 32 hr) - Fig. 18: dorsal vision; Fig. 19: ventral vision; Fig. 20: ventral vision of anterior end; Fig. 21: lateral vision of cephalopharyngeal skeleton; Fig. 22: ventral vision of posterior end; Fig. 23: anterior spiracle; Fig. 24: posterior spiracle. Abbreviations: aa= antenna; $a=$ maxilla (buccal hook); $b=$ dental sclerite (dentate); $\mathrm{d}=$ hypopharyngeal sclerite (infra-hypostomal); $\mathrm{f}=$ pharyngeal sclerite; $\mathrm{g}=$ hypostomal sclerite (parastomal or paraclypeal bar); $\mathrm{h}=$ clypeum; $\mathrm{i}=$ clypeal $\operatorname{arch} ; \mathrm{j}=$ infrapharyngeal sclerite; $\mathrm{l}=$ oral cristae (atrium); $\mathrm{m}=$ salivary gland duct; $\mathrm{n}=$ median incision; $\mathrm{o}=$ dorsal horn; $\mathrm{p}=$ ventral horn; $\mathrm{q}=$ ocular depression; $\mathrm{r}=$ hypostomal sclerite; $\mathrm{s}=$ ventral chitinous ring; $\mathrm{a}$ '= peritrema; $b^{\prime}=$ fissure; $c^{\prime}=$ spiracular opening; $d^{\prime}=$ spiracular orifice; $e^{\prime}=$ spiracular plate; $f^{\prime}=$ spiracular ramifications; $g$ '= spiracular chamber; $\mathrm{SC}=$ cephalopharyngeal skeleton; $\mathrm{SA}=$ anterior spiracle; $\mathrm{SP}=$ posterior spiracle; $\mathrm{TA}=$ anal tubercle; $\mathrm{VE}=$ external ventral tubercle; $\mathrm{VM}=$ ventromedial tubercle; $\mathrm{VI}=$ internal ventral tubercle; $\mathrm{VL}=$ ventrolateral process; $\mathrm{DE}=$ external dorsal tubercle; $\mathrm{DL}=\mathrm{dorso}-$ lateral process; $\mathrm{DI}=$ internal dorsal tubercle; $\mathrm{DM}=$ dorso medial tubercle; $\mathrm{DL}=$ dorsolateral process; $\mathrm{LD}=$ laterodorsal process; $\mathrm{LV}=$ lateroventral process. 


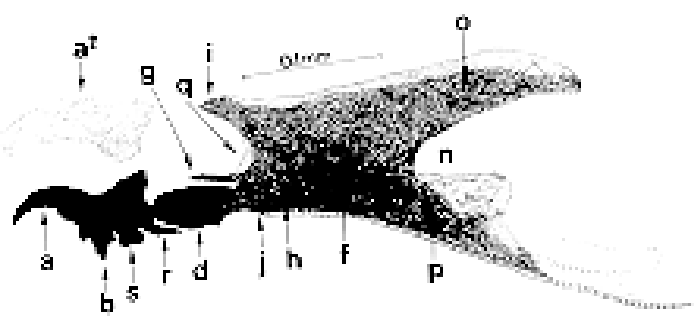

25

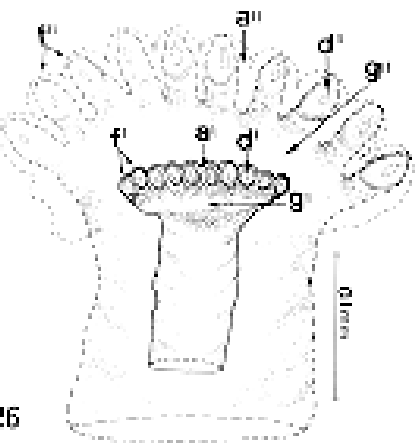

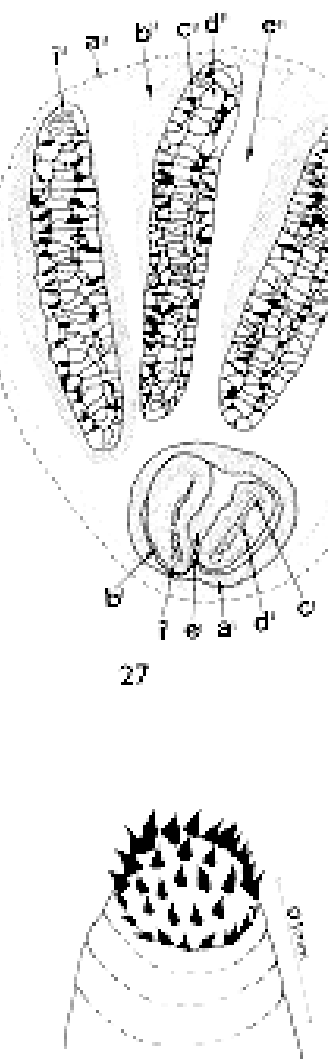

29

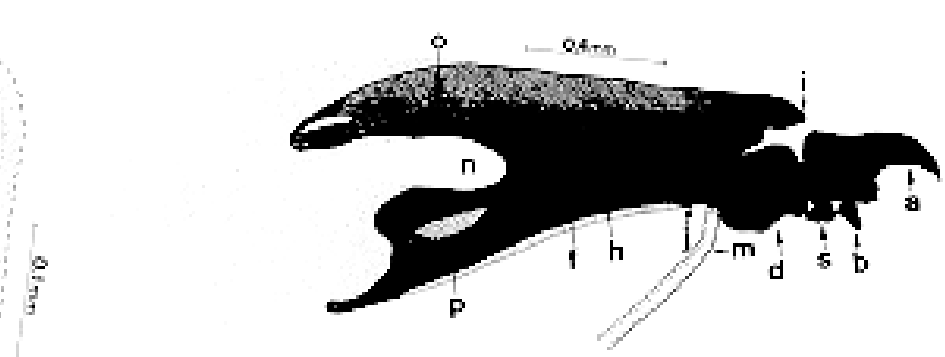

28

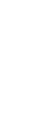

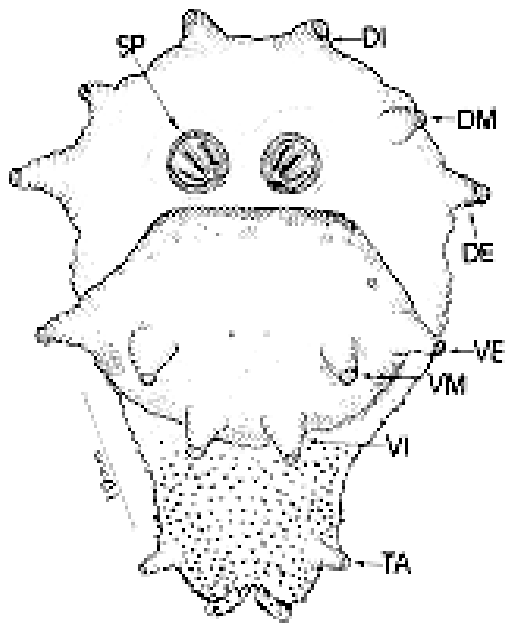

30

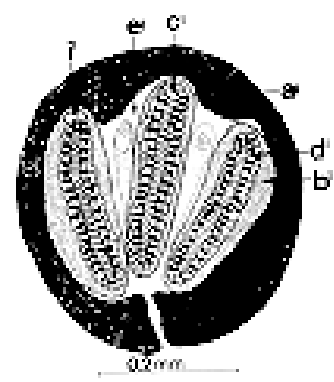

37

Transition from second to third larval instar (pharata) of Chrysomya albiceps. (From 25 to 27, second instar) - Fig. 25: lateral vision of cephalopharingeal skeleton (duration: $38 \mathrm{hr}$ ); Fig. 26: ventral vision of anterior spiracle (duration: $38 \mathrm{hr}$ ); Fig. 27: ventral vision of posterior spiracle (duration: $38 \mathrm{hr}$ ); (from 28 to 31, third instar): Fig. 28: lateral vision of cephalopharyngeal skeleton; Fig. 29: internal dorsal tubercle of detail; Fig. 30: ventral vision of posterior end; Fig. 31: posterior spiracle. Abbreviations: $a=$ maxilla (buccal hook); $b=$ dental sclerite (dentate); $d=$ hypopharyngeal sclerite (infra-hypostomal); $f=$ pharyngeal sclerite; $\mathrm{g}=$ hypostomal sclerite (parastomal or paraclypeal bar); $\mathrm{h}=$ clypeum; $\mathrm{i}=$ clypeal arch; $\mathrm{j}=\mathrm{infrapharyngeal}$ sclerite; $\mathrm{m}=$ salivary gland duct; $\mathrm{n}=$ median incision; $\mathrm{o}=$ dorsal horn; $\mathrm{p}=$ ventral horn; $\mathrm{q}=$ ocular depression; $\mathrm{r}=$ hypostomal sclerite; $\mathrm{s}=$ ventral chitinous ring; a', a"= peritrema; b', b"= fissure; $c^{\prime}, c^{\prime \prime}=$ spiracular opening; $d$ ', d"= spiracular orifice; $e^{\prime}$, e"= spiracular plate; f', f"= spiracular ramifications; g', g"= spiracular chamber; i', i" = trabeculae; TA= anal tubercle; VE= external ventral tubercle; $\mathrm{VM}=$ ventromedial tubercle; $\mathrm{VI}=$ internal ventral tubercle; $\mathrm{DI}=$ internal dorsal tubercle; $\mathrm{DM}=$ dorso medial tubercle; $\mathrm{DE}=$ external dorsal tubercle; $\mathrm{SP}=$ posterior spiracle. 


\section{DISCUSSION}

The larvae of $C$. albiceps can be easily distinguished from the congeneric ones, by the following combination of characteres: presence of three pairs of tubercles on the dorsal surface and three on the ventral surface, with those of the dorsal surface being more developed than those of the ventral surface.

In many aspects $C$. rufifacies and $C$. albiceps are very similar. Although the first species has never been recorded in Brazil, its presence was registered in South America (Buenos Aires, Argentina) by Mariluis and Schnack (1989) in January 1987, what makes possible its occurence in Brazil. The characterization of the larval instars of the $C$. albiceps will help the differentiation between them.

Ishijima (1967) observed that each segment of third instar larvae of $C$. rufifacies has long tubercles on the dorsal and ventral surface; these tubercles were also observed by Queiroz and Carvalho (1987) in C. albiceps. Liu and Greenberg (1989), working with second and third instar larvae of $C$. rufifacies, observed that second instar larvae presented small tubercles on the fourth segment and tubercles of normal size on the dorsal and ventral surface of the 5th to the 12th segment, while they presented small processes with many spicular processes grouped at their ends on the ventral surface of the third instar, which were comparable in size to the tubercles of the 5th to 11th segments. The last segment (12th) presented a posterior margin with pronounced triangular and flat tubercles, and not conical ones as in the other calliphorids. Liu and Greenberg (1989) also observed that the margins of the 12th segment of first instar larvae of $C$. rufifacies, Cochliomyia macellaria (Fabricius, 1775 ) and Phaenicia sericata (Meigen, 1826) presented small hairs which were actually small spines, and the peritrema of third instar larvae was incomplete in the first two species and had a spiracular bud in the third. These results agree with those obtained in the present study, since we visualized small spines in all instars of $C$. albiceps.

Menees (1962) discussed the hypothesis stated by several other authors about the nature and homology of the buccal hooks of dipteran larvae and commented upon some theories. Weisman (1864) and Becker (1910) (in Menees 1962) suggested that, with instar development the buccal hooks may be the structures that are fully reconstructed for larval use. He also proposed that it cannot be stated, as done by Holngrem (1904) and Ludwig (1949) (in Menees 1962), that the buccal hooks are the mandibles. According to Bischoff (1942) and Cook (1943) (in Menees 1962), due to the fusing inten- sity, the buccal hooks either are the maxillae or are mainly the maxillae with fusion of the mandibular elements, thus being mainly of mandibular origin.

Lopes (1982), in a study of the morphology of Cochliomyia hominivorax (Coquerel, 1858), C. macellaria and C. albiceps, observed that the cephalopharyngeal skeleton of the first larval instar had fundamental structures previously observed by him (Lopes 1943) in Musca domestica (Linneu, 1758): a series of conspicuous spines reaching up to the margins of the atrium, poorly developed maxillae and wide mandibles. He also observed that $C$. albiceps was similar to C. macellaria and C. hominivorax, and was differentiated from them by the presence of widened maxillae and a large hypostomal sclerite. Our results agree with those of Lopes (1982), but we further observed that $C$. hominovorax differs from $C$. macellaria and $C$. albiceps by the absence of a clypeal arch (frequent in true parasites) and by the presence of wider spines on the first thoracic segment.

Ishijima (1967) and Prins (1982) observed the presence of an accessory oral sclerite in Chrysomya regalis (Robineau-Desvoidy, 1830) which was club-shaped in Chrysomya pinguins (Walker, 1858) and small and comma-shaped in C. megacephala.

Erzinçlioglu (1989) observed that the cephalopharyngeal skeleton of Lucilia cuprina (Wiedemann, 1830) and L. sericata (Meigen, 1826) differs from that of $C$. putoria and $C$. albiceps by the presence of an accessory oral sclerite in the first two species, with the cephalopharyngeal skeleton being more robust in $C$. putoria and $C$. albiceps. The present study supports the results of this investigator, who observed the absence of an accessory oral sclerite in C. albiceps. Lopes (1943) also observed the absence of this sclerite in all M. domestica instars.

In a study of $C$. megacephala and Chrysomya chloropyga (Wiedemann, 1830), Prins (1979) observed that the buccal hook of C. megacephala presents a widely convex process with a slightly rounded angle on the upper basal surface; C. chloropyga has a flat dorsal surface and a flat, slightly concave, posterior surface, and the upper basal surface is slightly increased in a more acute angle. These traits disagree with those detected here in C. albiceps. According to Zumpt (1965), the distance between the two posterior peritremas may be used to distinguish some species, although Prins (1979), in a study of some specimens of $C$. megacephala and $C$. chloropyga, observed that distinction of these species on the basis of these traits seems to be impossible, since both have an open peritrema and are easily distinguishable from L. sericata, which has a closed peritrema. 
According to Ishijima (1967), third instar larvae of $C$. rufifacies have an anterior spiracle with 11 to 12 spiracular branchiae (ramifications); the cephalopharyngeal skeleton is wide and strongly pigmented, the dorsal horn is small and the ventral one is long, with a shallow and narrow incision between them; the accessory oral sclerite is absent; the hypostomal sclerite is small and robust; the posterior spiracle is wide and strongly pigmented; the peritrema is robust and closed, presenting two prominent projections between the spiracular openings; the bud is barely pigmented, with a small and wide spiracular opening. The results obtained here for $C$. albiceps do not agree with some of the characteristics detected in $C$. rufifacies by Ishijima (1967). We noted that this species presents a dorsal horn (pigmented zone) equal in size to the ventral horn and a posterior non-pigmented area continuous with the dorsal and ventral horns, which is larger in the dorsal horn; the peritrema is robust and open, with two prominent structures between the spiracular openings, which we believe to have a support function; the spiracular bud is absent.

Queiroz and Carvalho (1987) observed that third instar larvae of $C$. albiceps have an anterior spiracle with 11 branchiae and a barely visible bud. According to Zumpt (1965), there is a variation in the number of branchiae of the anterior spiracle, ranging from 11 to 12 , and the peritrema may be open or closed. Some of our results do not confirm those of Queiroz and Carvalho (1987) or Zumpt (1965) since we observed that the ramifications (branchiae) of the anterior spiracle ranged from 10 to 12, with no spiracular bud; and all the 240 specimens studied (third instar) presented an open peritrema.

According to Greenberg and Szyska (1984), $C$. putoria has an anterior spiracle with 10 to 12 branchiae, a posterior spiracle with an incomplete peritrema and absent bud; in $C$. macellaria the anterior spiracle has 8 to 12 branchiae, the peritrema is incomplete and the button is barely visible; $P$. cuprina has 5 to 6 branchiae, a complete well-pigmented peritrema and a bud.

\section{REFERENCES}

Baumgartner DL 1988. Spread of introduced Chrysomya blowflies (Diptera, Calliphoridae) in the neotropics with records new to Venezuela. Biotropica 20: 167168.

Baumgartner DL 1993. Review of Chrysomya rufifacies (Diptera, Calliphoridae). J Med Entomol 30: 338352.

Erzinçlioglu YZ 1987. The larvae of some blow-fliesof medical and veterinary importance. Med Vet Entomol 1: 121-125.

Erzinçlioglu YZ 1989. The early larval instars of Lucilia sericata and Lucilia cuprina (Diptera, Calli- phoridae): myiasis blowflies of Africa and Australia. J Nat History 23: 1133-1136.

Greenberg B, Szyska ML 1984. Immature stages and biology of fifteen species of Peruvian Calliphoridae (Diptera). Ann Entomol Soc Am 77: 488-517.

Guimarães JH, Prado AP, Linhares AX 1978. Three newly introduced blowfly species in southern Brasil (Diptera, Calliphoridae). Rev Bras Entomol 22: 5360.

Ishijima H 1967. Revision of the third stage larvae of synantropic flies of Japan (Diptera: Anthomyidae, Muscidae, Calliphoridae and Sarcophagidae). Japan J Sanit Zool 18: 47-100.

Kurahashi H 1981. Blow flies from Fiji, with descriptions of three new species of the genus Onesia (Diptera, Calliphoridae). Pac Insects 23: 434-444.

Liu D, Greenberg B 1989. Immature stages of some flies of forensic importance. Ann Entomol Soc Am 82: 80-93.

Lopes HS 1943. Contribuição ao conhecimento das larvas dos Sarcophagidae com especial referência ao esqueleto cefálico (Diptera). Mem Inst Oswaldo Cruz. 38: 127-163.

Lopes HS 1982. The importance of the mandible and clypeal arch of the first instar larvae in the classification of the Sarcaphagidae (Diptera). Rev Bras Entomol 26: 293-326.

Mariluis JC, Schnack JA 1989. Ecology of the blow flies of an eusynanthropic habitat near Buenos Aires (Diptera, Calliphoridae). Eos 65: 93 -101.

Mcalpine JF, Peterson BV, Shewell GE, Teskey JH, Vockeroth JR, Wood DN 1981. Manual of Neartic Diptera. Biosystematic Research Institute, Ottawa, Ontario. Research Branch Agriculture Canada. Vol. 1. Monograph 27.

Menees JH 1962. The skeletal elements of the gnathocephalon and its appendages in the larval of higher Diptera. Ann Entomol Soc Am 55: 607-616.

Patton WS 1922. Some notes on Indian Calliphorinae, part IV. Chrysomya albiceps Wied. (rufifacies Froggatt); one of the Australian sheep maggot flies and Chrysomya Villeneuvii, sp. nov. Indian. J Med Res 9: 561-569.

Prado AP, Guimarães JH 1982. Estado atual de dispersão e distribuição do gênero Chrysomya RobineauDesvoidy na região neotropical (Diptera, Calliphoridae). Rev Bras Entomol 26: 225-231.

Prins AJ 1979. Discovery of the oriental latrine fly Chrysomyia megacephala (Fabricius) along the south western coast of South Africa. Ann S Afr Mus 78: 39-47.

Prins AJ 1982. Morphological and biological notes on six south African blow-flies (Diptera, Calliphoridae) and their immature stages. Ann S Afr Mus 90: 201217.

Queiroz SM, Carvalho CJB 1987. Chave pictórica e descrições de larvas de $3^{\circ}$ ínstar de diptera (Calliphoridae, Muscidae e Fannidae) em vazadouros e resíduos sólidos domésticos em Curitiba, PR. Ann Soc Entomol Bras 16: 165-188.

Queiroz MMC, Milward-de-Azevedo EMV 1991. Técnicas de criação e alguns aspectos da biologia 
de Chrysomya albiceps (Wiedemann) (Diptera, Calliphoridae), em condições de laboratório. Revta Bras Zool 8: 75-84.

Richard RD, Gerrish RR 1983. The first confirmed field case of myiasis produced by Chrysomya sp. (Diptera, Calliphoridae) in the continental united states. J Med Entomol 20: 685.
Tantawi TI, Greenberg B 1993. Chrysomya albiceps and C. rufifacies (Diptera: Calliphoridae): Contribution to an Ongoing Taxonomic Problem. J Med Entomol 30: 646-648.

Zumpt F 1965. Myiasis in man and animals in the old world. Butterworths, London, 267 pp. 